\title{
Toward enteral nutrition in the treatment of pediatric Crohn disease in Canada: A workshop to identify barriers and enablers
}

\author{
Johan Van Limbergen MD FRCPCH PhD ${ }^{1,2,15}$, Jennifer Haskett BSNH, PDt ${ }^{1}$, Anne M Griffiths MD ${ }^{3}$, Jeff Critch MD MSc ${ }^{4}$, \\ Hien Huynh MBBS FRCPC ${ }^{5}$, Najma Ahmed MD', Jennifer C deBruyn MD ${ }^{7}$, Robert Issenman MD FRCP8, \\ Wael El-Matary MD ${ }^{9}$, Thomas D Walters $M D^{3}$, Cheryl Kluthe RN BScN5 ${ }^{5}$ Marie-Eve Roy RD ${ }^{10}$, Elizabeth Sheppard RN BN4, \\ Wallace V Crandall MD ${ }^{11}$, Stan Cohen MD ${ }^{12}$, Frank M Ruemmele MD PhD ${ }^{13}$, \\ Arie Levine $\mathrm{MD}^{14}$, Anthony R Otley MD MSc FRCPC ${ }^{1,15}$
}

\begin{abstract}
J Van Limbergen, J Haskett, AM Griffiths, et al. Toward enteral nutrition in the treatment of pediatric Crohn disease in Canada: A workshop to identify barriers and enablers. Can J Gastroenterol Hepatol 2015;29(7):351-356.
\end{abstract}

The treatment armamentarium in pediatric Crohn disease (CD) is very similar to adult-onset $\mathrm{CD}$ with the notable exception of the use of exclusive enteral nutrition (EEN [the administration of a liquid formula diet while excluding normal diet]), which is used more frequently by pediatric gastroenterologists to induce remission. In pediatric $C D$, EEN is now recommended by the pediatric committee of the European Crohn's and Colitis Organisation and the European Society for Paediatric Gastroenterology Hepatology and Nutrition as a firstchoice agent to induce remission, with remission rates in pediatric studies consistently $>75 \%$. To chart and address enablers and barriers of use of EEN in Canada, a workshop was held in September 2014 in Toronto (Ontario), inviting pediatric gastroenterologists, nurses and dietitians from most Canadian pediatric IBD centres as well as international faculty from the United States and Europe with particular research and clinical expertise in the dietary management of pediatric CD. Workshop participants ranked the exclusivity of enteral nutrition; the health care resources; and cost implications as the top three barriers to its use. Conversely, key enablers mentioned included: standardization and sharing of protocols for use of enteral nutrition; ensuring sufficient dietetic resources; and reducing the cost of EEN to the family (including advocacy for reimbursement by provincial ministries of health and private insurance companies). Herein, the authors report on the discussions during this workshop and list strategies to enhance the use of EEN as a treatment option in the treatment of pediatric CD in Canada.

Key Words: Crohn disease; Exclusive enteral nutrition; Nutritional therapy; Pediatrics
Vers l'alimentation entérique pour le traitement de la maladie de Crohn en pédiatrie au Canada : un atelier pour déterminer les obstacles et les catalyseurs

L'arsenal thérapeutique de la maladie de Crohn (MC) pédiatrique est très similaire à celui de la $\mathrm{MC}$ qui se déclare chez les adultes, à l'exception importante de l'alimentation entérale exclusive (AEE [l'administration d'une préparation liquide qui exclut un régime normal]), plus utilisée par les gastroentérologues pédiatres pour induire une rémission. En cas de MC pédiatrique, l'AEE est désormais recommandée comme agent de première intention pour induire une rémission par le comité pédiatrique de l'European Crohn's and Colitis Organisation et par la Société européenne de gastroentérologie, d'hépatologie et de nutrition pédiatrique. Selon des études en pédiatrie, le taux de rémission est constamment supérieur à $75 \%$. Afin de décrire et d'examiner les catalyseurs et les obstacles à l'utilisation de l'AEE au Canada, un atelier a eu lieu en septembre 2014 à Toronto, en Ontario, auquel était invités les gastroentérologues, les infirmières et les diététistes spécialisés en pédiatrie de la plupart des centres de MII pédiatriques du Canada, ainsi que des conférenciers internationaux des États-Unis et de l'Europe ayant des compétences de recherche et de clinique dans la prise en charge diététique de la $\mathrm{MC}$ pédiatrique. Les participants à l'atelier ont classé l'exclusivité de l'alimentation entérale, les ressources en santé et les coûts comme les trois principaux obstacles à son utilisation. En revanche, les principaux catalyseurs étaient la standardisation et le partage des protocoles sur l'utilisation de l'alimentation entérale, l'assurance de ressources alimentaires suffisantes et la réduction des coûts de l'AEE pour les familles (y compris la promotion de son remboursement par les ministères de la santé provinciaux et les sociétés d'assurance privées). Dans le présent article, les auteurs rendent compte des échanges pendant l'atelier et dressent une liste des stratégies visant à améliorer l'utilisation de l'AEE comme option thérapeutique de la MC pédiatrique au Canada.
Crohn disease (CD) presents during childhood or adolescence in up to $25 \%$ of patients and is typically more extensive than adult-onset disease $(1,2)$. Incidence rates in Canada are among the highest reported worldwide (3). Whereas teenagers with CD often progress toward pene- trating complications in a rate similar to adult-onset $\mathrm{CD}$, very early onset CD ( $<6$ years of age at diagnosis, excluding monogenic forms of very early onset inflammatory bowel disease [IBD]) is associated with fewer hospitalizations and surgery $(2,4)$. The treatment armamentarium

${ }^{1}$ Division of Gastroenterology $\mathcal{E}$ Nutrition, Department of Pediatrics, IWK Health Centre; ${ }^{2}$ Department of Microbiology and Immunology, Dalhousie University, Halifax, Nova Scotia; ${ }^{3}$ Division of Pediatric Gastoenterology, Hepatology and Nutrition, Hospital for Sick Children, Toronto, Ontario; ${ }^{4}$ Division of Pediatric Gastroenterology, Janeway Child Health Centre, St John's, Newfoundland Ë Labrador; 5 Division of Pediatric Gastroenterology, Stollery Children's Hospital, University of Alberta, Edmonton, Alberta; ${ }^{6}$ Division of Pediatric Gastroenterology and Nutrition, Department of Pediatrics, Montreal Children's Hospital, McGill University, Montreal, Quebec; 7 Division of Gastroenterology and Nutrition, Department of Paediatrics, University of Calgary, Calgary, Alberta; ${ }^{8}$ Division of Pediatric Gastroenterology and Nutrition, McMaster Children's Hospital, Hamilton, Ontario; ${ }^{9}$ Section of Pediatric Gastroenterology, Department of Pediatrics, College of Medicine, Faculty of Health Sciences, University of Manitoba, Winnipeg, Manitoba; ${ }^{10}$ Department of Pediatric Gastroenterology, Hepatology and Nutrition, Centre Hospitalier Universitaire Sainte-Justine, Montréal, Québec; ${ }^{11}$ Division of Pediatric Gastroenterology, Hepatology and Nutrition, Nationwide Children's Hospital and The Ohio State University, Columbus, Ohio; ${ }^{12}$ Children's Center for Digestive Health Care, Children's Healthcare of Atlanta, Atlanta, Georgia, USA; ${ }^{13}$ Université Sorbonne Paris Cité, Université Paris Descartes, INSERM U989, Service de Gastroentérologie Pédiatrique, Hôpital Necker Enfants Malades, Paris, France; ${ }^{14}$ Pediatric Gastroenterology and Nutrition Unit, Wolfson Medical Center, Sackler School of Medicine, Tel-Aviv University, Tel-Aviv, Israel; ${ }^{15}$ Division of Gastroenterology, Faculty of Medicine, Dalhousie University, Halifax, Nova Scotia

Correspondence: Dr Anthony R Otley, Department of Pediatrics, Dalhousie University, Division of Pediatric Gastroenterology $\mathcal{E}$ Nutrition, IWK Health Centre, 5850/5980 University Avenue, PO Box 9700, Halifax, Nova Scotia B3K 6R8. Telephone 902-470-8225, fax 902-470-7249, e-mail arotley@dal.ca Received for publication March 3, 2015. Accepted March 7, 2015 
in pediatric $\mathrm{CD}$ is very similar to adult-onset $\mathrm{CD}$ with the exception of the frequent use of exclusive enteral nutrition (EEN [the administration of a liquid formula diet while excluding normal diet]), which is used more often by pediatric gastroenterologists. In pediatric CD, EEN is now recommended by the pediatric committee of the European Crohn's and Colitis Organisation (ECCO), and the European Society for Paediatric Gastroenterology Hepatology and Nutrition (ESPGHAN) as a first-choice agent to induce remission, with remission rates in pediatric studies consistently $>75 \%$, and is also commonly used in Japan and Australasia (5). The effectiveness of EEN was first described in adult patients with severe disease (6-9). In view of safety concerns of combination immunosuppressive therapy and because of increasing patient interest in dietary therapy, EEN is now also regaining momentum as a treatment option in adult CD (10-16).

Long-term dietary patterns and specific food items have been shown to influence risk of CD development in all age groups (17-19). Nutritional approaches once CD is established have included total parenteral nutrition, specific dietary exclusions, partial enteral nutition (EN) and avoidance of all dietary intake using EEN (19-22). Avoidance of all dietary intake using a complete nutritional alternative, such as EEN, has been shown to be superior to partial EN when the additional oral dietary intake is not controlled (23). Recent case series of successful use of specific exclusion diets (alone or in combination with EN) as well as requests from many patients to further develop evidence-based dietary therapy, require confirmation by controlled dietary intervention studies $(24,25)$.

Achieving mucosal healing (or endoscopic improvement) has gained support as therapeutic target in CD and may dramatically reduce the risk for long-term disease complications including surgery (26). In small controlled studies, EEN has been shown to be superior to steroids in achieving mucosal healing, while being notably free from important adverse events (20,27-29). EEN has demonstrated efficacy at first induction of clinical remission as well as for subsequent flares, even in patients who have lost response to anti-tumour necrosis factor (TNF) therapy $(20,25,29,30)$. Recently, the GROWTH CD study (a prospective, outcome-based study in newly diagnosed untreated pediatric patients with CD, conducted in Europe and Israel, established by the Porto Group of ESPGHAN, NIH NCT00711945) showed that in mild-to-moderate CD, EEN was superior to steroids both when considering remission according to the Pediatric Crohn's Disease Activity Index (PCDAI) (OR 5.8 [95\% CI 1.8 to 18.3]) or combined normal PCDAI and C-reactive protein (OR 3.4 [95\% CI 1.3 to 9]) (31).

The use of EN for maintenance of remission varies across IBD centres in terms of strategies used (eg, overnight versus supplemental day time, percentage of total daily calories, as monotherapy or in combination with immunomodulators/anti-TNF) (10,12,15,32-37). Research is ongoing with regard to the optimal maintenance strategy (eg, Cyclic Exclusive Enteral Nutrition as Maintenance Therapy for Pediatric Crohn's Disease [CD-HOPE; NCT02201693] by GETAID pédiatrique) but uncertainty with regard to its use during maintenance of remission could deter from using EEN as induction therapy. In adults and children with CD alike, quality of life using EEN improves even before mucosal healing is obtained (38-40).

The phenotype of CD that is suitable to be treated with EEN, particularly whether isolated colonic disease will respond, has long been a subject of debate $(22,28,29,41-44)$. Clearly, any liquid diet may cause difficulties in terms of stool consistency and frequency, which can be troublesome in the presence of left-sided colonic disease (and, therefore, increase the PCDAI subscore). Afzal et al (42) reported that the achieved remission rate for isolated colonic disease (50\% [seven of 14]) was less than in ileal (92\% [11 of 12]) or ileocolonic disease (82\% [32 of 39]) ( $\mathrm{P}=0.02)$. However, subsequent case series did not report this different remission rate $(22,41)$. In the study by Buchanan et al (41), isolated colonic disease (without upper gastrointestinal disease, as categorized according to the Vienna classification) achieved a remission rate of $79 \%$, although not assessed prospectively by customary disease activity measures. Given these discrepancies, it would appear reasonable to consider use of EEN for all patients with luminal $\mathrm{CD}$. Perianal $\mathrm{CD}$ or the presence of severe colonic disease are listed in the ECCO/ESPGHAN guidelines as factors that warrant consideration of other induction therapy (5).

In this era of balancing treatment-associated risks with maximum effectiveness, yet with appropriate attention for patient-reported outcomes, it is timely to address why EEN is not used more widely across North America $(9,45)$. In fact, there are significant variations in the patterns of use and the acceptance of EEN by physicians between Canada and the United States: Canadian physicians show a greater use of EEN (46). Despite growing concerns about the safety profile of corticosteroids, these geographical variations have not changed over the past 15 years $(45,46)$. The use of EEN appears to be influenced by the extent to which physicians are exposed to its use both in their training and in their current practice setting $(46,47)$. To chart and address enablers and barriers of use of EEN in Canada, a workshop was held in September 2014 in Toronto (Ontario), inviting pediatric gastroenterologists, nurses and dietitians from most Canadian pediatric inflammatory bowel disease centres as well as international faculty from the United States and Europe with particular research and clinical expertise in the dietary management of pediatric CD. In the present report, we discuss the findings of this workshop dedicated to enhancing the use of EEN as a treatment option in the treatment of pediatric CD in Canada.

\section{Preworkshop findings}

Before the workshop, individual telephone interviews were conducted by a consumer insights professional with 11 patient families from various clinics across Canada to begin to explore the patient and family experience of choosing a treatment option. Of the 11 patients, seven had received some form of EN as part of their initial treatment. These data were grouped according to theme (Table 1) and formed part of the workshop discussions.

\section{Workshop}

Twenty pediatric stakeholders attended the one-day workshop, including three nurses, two dietitians and 15 pediatric gastroenterologists. Participants completed a premeeting assignment identifying experience in their pediatric practice with barriers and enablers to using EEN related to the following influencers: health system (internal and external), patient/family, EN, physician/care team-related or other. During the workshop, participants worked in groups and further refined and categorized the submitted responses, and discussed potential solutions to barriers and ways to enhance enablers (Table 2). These results were further ranked according to priority, highlighting similar barriers and enablers to the use of EEN as described in the literature.

Significant barriers to the use of EEN can be related to:

\section{EEN mechanism of action: requirement of exclusivity}

2. Patient/family adherence: oral versus nasogastric (NG) tube

3. Health care team/health care system/insurance

Consideration of priority of barriers and enablers to the use of EEN After an iterative process of discussion, health care participants of the workshop consistently ranked: the exclusivity of EN; the health care resources; and cost implications as the top three barriers to its use (Table 2). Conversely, key enablers repeatedly mentioned included: standardization and sharing of protocols for use of EN (including approach in clinic to EEN, which is heavily influenced by the exposure of the health care team to the benefits of EEN during their training) as well as mode of delivery; ensuring sufficient dietetic resources; and reducing the cost of EEN to the family (including advocacy for reimbursement by provincial ministries of health and private insurance companies). As will be discussed below, emphasizing the need to completely avoid the prediagnosis oral diet by means of EEN, as a requirement to achieve successful induction of remission, can help address some of these barriers and enablers. 
TABLE 1

Thematic summary of patient and family interviews

\begin{tabular}{|c|c|}
\hline Factors/themes (with examples) & $\begin{array}{l}\text { Considerations and impact } \\
\text { on practice after discussion } \\
\text { in workshop }\end{array}$ \\
\hline \multicolumn{2}{|l|}{ Messaging from health care team } \\
\hline $\begin{array}{l}\text { "Pharmacist said incidence of most } \\
\text { side effects from steroids were } 10 \% \\
\text { or lower". } \\
\text { - Family opted for the steroid because } \\
\text { they did not feel the efficacy of the } \\
\text { EEN was explained }\end{array}$ & $\begin{array}{l}\text { - Need for multidisciplinary } \\
\text { education and conviction; } \\
\text { ensure accurate and consistent } \\
\text { messaging } \\
\text { - Written information to ensure } \\
\text { accurate recall by families }\end{array}$ \\
\hline \multicolumn{2}{|l|}{ Parental assumptions and expectations } \\
\hline $\begin{array}{l}\text { - "at } 14, \text { no way would she do that" } \\
\text { " } 12 \text { is a difficult, in-between age. } \\
\text { Maybe if he was younger or older he } \\
\text { would (been convinced to) have tried } \\
\text { the [formula]." }\end{array}$ & $\begin{array}{l}\text { - Importance of connecting } \\
\text { parents with experienced } \\
\text { parents } \\
\text { - Involve social work or health } \\
\text { psychology }\end{array}$ \\
\hline \multicolumn{2}{|l|}{ Social concerns } \\
\hline $\begin{array}{l}\text { - Integration into school, activities, } \\
\text { not eating } \\
\text { - "EEN would be socially isolating" } \\
\text { - "patient became emotional about } \\
\text { not eating (worried about missing } \\
\text { the food he liked; being different } \\
\text { from his friends)" }\end{array}$ & $\begin{array}{l}\text { Importance of connecting } \\
\text { patients to youth with EEN } \\
\text { experience, use available } \\
\text { resources (videos, camp/ } \\
\text { social experience) }\end{array}$ \\
\hline \multicolumn{2}{|l|}{ Guilt } \\
\hline $\begin{array}{l}\text { - Parents felt that he had already been } \\
\text { through so much that they did not } \\
\text { want to upset him further } \\
\text { - "At } 10 \text { or } 11 \text {, it was hard to imagine } \\
\text { that he could only drink when his } \\
\text { friends were eating" }\end{array}$ & $\begin{array}{l}\text { - Focus on benefits of EEN, } \\
\text { not only challenges } \\
\text { - Importance of connecting } \\
\text { parents with experienced } \\
\text { parents } \\
\text { - Involve social work or health } \\
\text { psychology }\end{array}$ \\
\hline \multicolumn{2}{|l|}{ Child as the decision maker } \\
\hline $\begin{array}{l}\text { "Parents have to respect the wishes } \\
\text { of their children (even very young } \\
\text { children). The option of a steroid } \\
\text { was the only one our son wanted } \\
\text { to look at, so we had to go with his } \\
\text { wishes." (Pt was } 10 \text { years old when } \\
\text { EEN was offered) } \\
\text { "You can't make your teen do what } \\
\text { they don't want to do" }\end{array}$ & $\begin{array}{l}\text { - Be sure child is present and } \\
\text { actively engaged in discus- } \\
\text { sions regarding treatment } \\
\text { - The child is a key player in } \\
\text { the decision making, but they } \\
\text { are not the only player - } \\
\text { parental involvement is also } \\
\text { important; a difficult decision } \\
\text { to make alone } \\
\text { - Engage supports - such as } \\
\text { peers - connect with patient } \\
\text { who has been on EEN }\end{array}$ \\
\hline \multicolumn{2}{|l|}{ Adaptation } \\
\hline $\begin{array}{l}\text { - "It seems so traumatic at first, but you } \\
\text { have to look ahead. There are so many } \\
\text { possibilities for a good outcome." } \\
\text { - "it is hard, but it will get a lot better" } \\
\text { - "nervous but relieved [at decision } \\
\text { to place NG tube]". The tube was } \\
\text { in for } 101 / 2 \text { weeks... Stayed in; } \\
\text { changed } 3 \text { times. Very successful. } \\
\text { She gained weight." }\end{array}$ & $\begin{array}{l}\text { - Have families share their } \\
\text { experiences and strategies }\end{array}$ \\
\hline
\end{tabular}

EEN Exclusive enteral nutrition; NG Nasogastric

The mechanism of action of EEN remains conjectural, but is suggested to involve modulation of gut microbial community (microbiota) composition, which is considered a critical factor in CD pathogenesis $(40,48)$. Although the microbiota is rapidly altered to a limited degree by dietary changes, the overall community structure (and presumed metabolic function) has been shown to be resilient to short-term dietary interventions (eg, 10 days in the CAFE study by Wu et al [49]) and is linked with long-term dietary patterns (49-52).
TABLE 2

Summarized barriers and enablers from group exercise

\begin{tabular}{|c|c|c|}
\hline Factor & Barriers & Enablers \\
\hline $\begin{array}{l}\text { Health system } \\
\text { internal (hospital/ } \\
\text { health authority) }\end{array}$ & $\begin{array}{l}\text { - Insufficient clinic } \\
\text { resources: allied } \\
\text { health staff, } \\
\text { knowledge, space* }\end{array}$ & $\begin{array}{l}\text { Adequate numbers of } \\
\text { trained team members } \\
\text { (nurses, dietitians, social } \\
\text { work/psychology/child } \\
\text { health) and dedicated } \\
\text { space for teaching* }\end{array}$ \\
\hline $\begin{array}{l}\text { Health system } \\
\text { external (provincial/ } \\
\text { regional) }\end{array}$ & $\begin{array}{l}\text { - Funding for sup- } \\
\text { plies, formula }\end{array}$ & $\begin{array}{l}\text { - Coverage for EEN } \\
\text { supplies and formula* } \\
\text { - Supportive home services }\end{array}$ \\
\hline Patient/family & $\begin{array}{l}\text { - Fear of NG tube } \\
\text { and/or loss of food } \\
\text { - Difficulty sustaining } \\
\text { diet } \\
\text { - Limited support to } \\
\text { family/socialization }\end{array}$ & $\begin{array}{l}\text { - Involving parents/family } \\
\text { in feeding choice } \\
\text { - Support of diet, acknowl- } \\
\text { edging it may be difficult } \\
\text { - Supportive dietitian } \\
\text { throughout process }\end{array}$ \\
\hline Enteral nutrition & $\begin{array}{l}\text { - Exclusivity of enteral } \\
\text { nutrition with no/ } \\
\text { limited oral intake* } \\
\text { - Cost of enteral } \\
\text { nutrition* } \\
\text { - Taste } \\
\text { - NG tube }\end{array}$ & $\begin{array}{l}\text { - Evidence-based/reduced } \\
\text { need for steroids } \\
\text { - Few side effects } \\
\text { - Oral option possible; } \\
\text { recipes }\end{array}$ \\
\hline $\begin{array}{r}\text { Physician/care } \\
\text { team-related }\end{array}$ & $\begin{array}{l}\text { - Lack of institutional } \\
\text { experience or critical } \\
\text { mass to "keep it } \\
\text { going"* } \\
\text { - Lack of } \\
\text { standardization of } \\
\text { enteral nutrition } \\
\text { approach* }\end{array}$ & $\begin{array}{l}\text { - Consistent and system- } \\
\text { atic approach to EEN } \\
\text { (protocols, tools, talking } \\
\text { points, defined roles for } \\
\text { team members) } \\
\text { - Conviction of physician } \\
\text { and team to support EEN } \\
\text { - Quality review process } \\
\text { - Resource sharing }\end{array}$ \\
\hline
\end{tabular}

$\overline{{ }^{*} B a r r i e r s}$ and enablers identified as highest priority. EEN Exclusive enteral nutirition; NG Nasogastric

Although the clinical and biochemical parameters of disease remission are often achieved by four weeks of induction treatment, the relapse rates of up to $60 \%$ by the end of the first year may suggest that the 'state' of the microbiome was not sufficiently shifted $(34,53,54)$. The duration of EEN varies substantially across published reports (9). This variation in practice can be linked with preferential use of oral versus NG tube-delivered EEN; although strict compliance with oral EEN (and avoidance of dietary intake) is achieved by many patients, for others it may be easier to sustain EEN via NG tube, with optimization of benefits beyond achieving normalization of inflammatory markers and clinical remission. The question of whether establishment of a new stable microbiome, away from the inflammation-associated 'state', can become a therapeutic goal, will need to be studied in prospective microbiome-focused trials. Gerasimidis et al (48) showed that EEN paradoxically reduces some of the presumed 'protective' features of the gut microbiota, such as community diversity and even particular bacterial species (eg, Firmicutes), making its mode of action difficult to infer $(25,48)$. Recent reports describing specific exclusion diets have rekindled the debate of whether the strong therapeutic effect of EEN is mediated largely by the avoidance of putative dietary triggers $(24,25)$. In other words, rather than actively inducing 'protective' microbiota changes, EEN may mediate remission by excluding dietary products that elicit pathological changes in gut microbiota composition/function and promote dysfunctional host-microbe interactions in the gut mucosa. Earlier trials of partial EN (50\% of total daily calories) were not successful in inducing clinical remission; however, more recent evidence indicates that this is perhaps because no dietary changes were made in the remaining $50 \%$ of non-EN calories $(23,55)$. Further support for the crucial role of exclusion of normal diet comes 
from the comparison of different types of dietary intervention (28). Although trials were not powered to the level of confirming noninferiority, comparison of remission rates for different compositions of formula used (eg, elemental versus polymeric, more/less long-chain triglycerides, etc) or additional additives (eg, glutamine), have not shown one type of formula to be superior (28). There is now an ongoing multicentre, randomized dietary intervention trial studying EEN versus EN plus a specific CD exclusion diet (NCT01728870 - clinicaltrials. gov) (25). Until the efficacy of these novel dietary interventions is shown, considering the benefits of EEN in terms of exclusion of other dietary intake can help overcome several barriers to its use.

To improve patient/family adherence, EEN could, thus, be presented as an effective treatment option by exclusion of the normal dietary intake, in addition to being an alternative to corticosteroid therapy. A consistent approach to discussing EEN in clinic significantly improves acceptance and compliance, as evident from the experience in many European centres $(34,41,53)$. Furthermore, achieving steroid-free maintenance of remission has become an accepted treatment goal in pediatric CD due to its multitude of beneficial effects on growth, nutritional status, bone health and avoiding infectious adverse events, particularly in combination with other immunosuppressive agents (56-58). Clinicians, patients and their families embark on steroid-based induction therapy with a view to early discontinuation but, without anti-TNF therapy, 30\% to $40 \%$ are steroid dependent after one year of follow-up in referral centre reports from the United States and Canada $(56,57)$. Krupoves et al (57) showed there were no temporal differences in the rates of corticosteroid dependency in pediatric CD before 2000 (43.9\%) and in subsequent years $(39.4 \% ; \mathrm{P}=0.411)$, and no differences between the two pediatric IBD centres contributing to this study (Montreal [St-Justine Hospital]) and Ottawa), although anti-TNF therapy was used in only $5 \%$ of this cohort.

Clearly, choosing an alternative to steroids as induction therapy then becomes a logical approach to avoid steroid dependence. For induction, EEN may be administered orally or via NG tube. Oral feedings are more common in Europe, Australia and some United States centres, whereas many Canadian centres use NG tube (however, for example, at Centre hospitalier universitaire Sainte-Justine [Montreal, Quebec] the majority of patients successfully adhere to oral EEN) (9). In a retrospective comparative study on mode of delivery of EEN (based on physician preference), there was no difference in clinical outcome: both were equally effective $(22,59)$. Up to $50 \%$ of patients may require an $\mathrm{NG}$ tube to complete a course of $\mathrm{EN}>6$ weeks (41). It is important to discuss treatment options in case of difficulty with adherence or failure of EEN, as well as planning for the strategy to maintain remission. The guidelines of the North American Society for Pediatric Gastroenterology, Hepatology and Nutrition (NASPGHAN) IBD Committee refer to an induction period of at least eight weeks with EEN (9). Given that both the time to initial benefit and then to clinical remission can vary, the NASPGHAN report also suggests a period of three to four weeks of EEN before a decision is made about effectiveness (9).

Because the majority of treatment for pediatric CD occurs outside the hospital, the success of EEN therapy is highly dependent on adequate health care resources needed for a home EN program, notably the composition and commitment of a multidisciplinary team. Explaining how lifestyle choices (including diet) impact on general health and development of disease has become accepted practice. Dietary changes impacting on the family and social life are already part of living with IBD for many patients $(19,60)$. Increasingly, patients and their families request, expect and accept dietary management as part of the treatment of $\operatorname{IBD}(60,61)$. Attitudes among health care staff to promote the use of EEN, the attending physician's exposure to dietary therapy during her/his training and the centre's experience are all key determinants of success of EEN $(9,46,56,57)$. Nursing and dietitian support to deliver this evidence-based dietary management is, therefore, ideal for a successful EEN program. Access to psychological support can also be important for many patients and families to increase coping skills with the disease in general and EEN treatment in particular (9). Planning and discussing strategies to integrate EEN into the family, school and social life, significantly increase adherence to EEN.

The practical considerations of any successful home EN program include the determination of caloric and other nutrient requirements, determining the best method of administration (oral versus NG, also depending on health care system/insurance stipulation as discussed below), scheduled support during the induction period (eg, by means of a care pathway identifying the role of each team member), and addressing expectations around the time to clinical benefits and total duration of therapy (9)

EEN and its administration (formula, NG tube, and supplies and feeding pump) can be an expensive intervention. Differences in health care systems in each province of Canada affect at-home reimbursement coverage for the formula and supplies, with different programs often required for each. There are well-established programs in some provinces (eg, Alberta, Ontario and Quebec); however, restrictions, such as administration via NG tube (eg, Alberta and Ontario) or the need for home care nursing support can be a condition/barrier to funding. In turn, individual hospitals may operate their own programs in provinces in which a provincial home EN program is lacking. Because funding for health care is provincially managed, there is significant variation across Canada, which affects the uptake of EEN as a therapeutic option.

There has been some limited success in obtaining coverage with private insurance in Canada, but the process is often cumbersome and lengthy. For instance, clinics are required to write individual letters for patients to insurance companies to request financial support. This often requires two to three letters to receive what may still be limited coverage. Clearly, a positive response may justify the effort needed to seek support for home EN, but this often adds considerably to the workload of the multidisciplinary team delivering EEN. In cases where coverage is disputed, it has often been helpful to emphasize the role of the formula as the therapeutic intervention, and the therapeutic requirement for a six- to 12 -week period to exclude all other dietary intake to achieve clinical remission.

\section{CONCLUSIONS}

EEN is an extremely safe but underused treatment for induction of remission in pediatric CD in North America. Guidelines from both the NASPGHAN IBD Committee as well as the recent ECCO/ ESPGHAN guidelines recommend use of EEN as first-line induction therapy in pediatric CD. During this thematic workshop focused on improving the framework for successful implementation of EEN therapy in pediatric CD in Canada, the panel ranked the need for EEN, the health care resources needed for a home EN program and cost implications as the top three barriers to its use. Identifying and understanding the barriers enables us to work on targeted strategies to overcome them, and help clinics implement and improve their success using EEN. Overcoming the barriers is the next step in the process.

Until we improve our understanding of the environmental and dietary triggers of $\mathrm{CD}$, the effectiveness of $\mathrm{EN}$ will continue to rely on exclusion of the 'prediagnosis' diet. A standardized yet individualized approach (ie, by considering the caloric and other nutrient requirements of each patient) will optimize the use of limited dietetic resources, ideally with additional support for home nutrition programs. Polymeric formulas (which tend to be less expensive and more palatable) may be better suited if the oral route is chosen, with the option of dietetic guidance to flavour the formula used to avoid taste fatigue. Reducing the cost of EEN to the family will require ongoing advocacy for reimbursement by provincial ministries of health and private insurance companies. Further research to enhance our understanding of the mechanisms of action and the optimal application of EEN (or partial EN with additional dietary modifications) is necessary. Until such time, EEN should be recommended and supported as a highly effective and safe treatment modality in CD. 
ACKNOWLEDGEMENTS: JVL was supported by a NASPGHAN/ CCFA Young Investigator Development Award (2013-2015), a Future Leaders in IBD research award 2014 and the Dalhousie Medical Research Foundation. Financial support was provided by Nestlé Health Science.

\section{REFERENCES}

1. Griffiths AM. Specificities of inflammatory bowel disease in childhood. Best Pract Res Clin Gastroenterol 2004;18:509-23.

2. Van Limbergen J, Russell RK, Drummond HE, et al. Definition of phenotypic characteristics of childhood-onset inflammatory bowel disease. Gastroenterology 2008;135:1114-22.

3. Benchimol EI, Fortinsky KJ, Gozdyra P, Van den Heuvel M, Van Limbergen J, Griffiths AM. Epidemiology of pediatric inflammatory bowel disease: A systematic review of international trends. Inflammatory Bowel Dis 2011;17:423-39.

4. Benchimol EI, Mack DR, Nguyen GC, et al. Incidence, outcomes, and health services burden of very early onset inflammatory bowel disease. Gastroenterology 2014;147:803-13.e7.

5. Ruemmele FM, Veres G, Kolho KL, et al. Consensus guidelines of ECCO/ESPGHAN on the medical management of pediatric Crohn's disease. J Crohns Colitis. 2014;8:1179-207.

6. O'Morain C, Segal AW, Levi AJ. Elemental diet as primary treatment of acute Crohn's disease: A controlled trial. BMJ 1984;288:1859-62.

7. O'Morain C, Segal AW, Levi AJ. Elemental diets in treatment of acute Crohn's disease. BMJ 1980;281:1173-5.

8. Gassull MA, Abad A, Cabre E, Gonzalez-Huix F, Gine JJ, Dolz C. Enteral nutrition in inflammatory bowel disease. Gut 1986;27(Suppl 1):76-80.

9. Critch J, Day AS, Otley A, King-Moore C, Teitelbaum JE, Shashidhar H. Use of enteral nutrition for the control of intestinal inflammation in pediatric Crohn disease. J Pediatr Gastroenterol Nutr 2012;54:298-305.

10. Kamata N, Oshitani N, Watanabe K, et al. Efficacy of concomitant elemental diet therapy in scheduled infliximab therapy in patients with Crohn's disease to prevent loss of response. Dig Dis Sci 2014. [Epub ahead of print]

11. Lee J, Allen R, Ashley S, et al. British Dietetic Association evidence-based guidelines for the dietary management of Crohn's disease in adults. J Human Nutr Dietetics 2014;27:207-18.

12. Li G, Ren J, Wang G, et al. Preoperative exclusive enteral nutrition reduces the postoperative septic complications of fistulizing Crohn's disease. Eur J Clin Nutr 2014;68:441-6.

13. Wall CL, Day AS, Gearry RB. Use of exclusive enteral nutrition in adults with Crohn's disease: A review. World J Gastroenterol 2013;19:7652-60

14. Lomer MC, Gourgey R, Whelan K. Current practice in relation to nutritional assessment and dietary management of enteral nutrition in adults with Crohn's disease. J Human Nutr Dietetics 2014;27(Suppl 2):28-35.

15. Yamamoto T, Shiraki M, Nakahigashi M, Umegae S, Matsumoto K. Enteral nutrition to suppress postoperative Crohn's disease recurrence: A five-year prospective cohort study. Int J Colorectal Dis 2013;28:335-40.

16. Watanabe $\mathrm{O}$, Ando $\mathrm{T}$, Ishiguro $\mathrm{K}$, et al. Enteral nutrition decreases hospitalization rate in patients with Crohn's disease. J Gastroenterol Hepatol 2010;25(Suppl 1):S134-7.

17. D'Souza S, Levy E, Mack D, et al. Dietary patterns and risk for Crohn's disease in children. Inflamm Bowel Dis 2008;14:367-73.

18. Hou JK, Abraham B, El-Serag H. Dietary intake and risk of developing inflammatory bowel disease: A systematic review of the literature. Am J Gastroenterol 2011;106:563-73.

19. Green TJ, Issenman RM, Jacobson K. Patients' diets and preferences in a pediatric population with inflammatory bowel disease. Can J Gastroenterol 1998;12:544-9.

20. Otley AR, Russell RK, Day AS. Nutritional therapy for the treatment of pediatric Crohn's disease. Expert Rev Clin Immunol 2010;6:667-76.

21. Levine A, Wine E. Effects of enteral nutrition on Crohn's disease: Clues to the impact of diet on disease pathogenesis. Inflamm Bowel Dis 2013;19:1322-9.

22. Rubio A, Pigneur B, Garnier-Lengliné $\mathrm{H}$, et al. The efficacy of exclusive nutritional therapy in paediatric Crohn's disease, comparing fractionated oral vs. continuous enteral feeding. Aliment Pharmacol Ther 2011;33:1332-9.
23. Johnson T, Macdonald S, Hill SM, Thomas A, Murphy MS. Treatment of active Crohn's disease in children using partial enteral nutrition with liquid formula: A randomised controlled trial. Gut 2006;55:356-61.

24. Cohen SA, Gold BD, Oliva S, et al. Clinical and mucosal improvement with specific carbohydrate diet in pediatric Crohn disease. J Pediatr Gastroenterol Nutr 2014;59:516-21.

25. Sigall-Boneh R, Pfeffer-Gik T, Segal I, Zangen T, Boaz M, Levine A. Partial enteral nutrition with a Crohn's disease exclusion diet is effective for induction of remission in children and young adults with Crohn's disease. Inflamm Bowel Dis 2014;20:1353-60.

26. Ruemmele FM, Hyams JS, Otley A, et al. Outcome measures for clinical trials in paediatric IBD: An evidence-based, expert-driven practical statement paper of the paediatric ECCO committee. Gut 2015;64:438-46.

27. Borrelli O, Cordischi L, Cirulli M, et al. Polymeric diet alone versus corticosteroids in the treatment of active pediatric Crohn's disease: A randomized controlled open-label trial. Clin Gastroenterol Hepatol 2006;4:744-53.

28. Zachos M, Tondeur M, Griffiths AM. Enteral nutritional therapy for induction of remission in Crohn's disease. Cochrane Database Syst Rev 2007:CD000542.

29. Wilschanski M, Sherman P, Pencharz P, Davis L, Corey M, Griffiths A Supplementary enteral nutrition maintains remission in paediatric Crohn's disease. Gut 1996;38:543-8.

30. Frivolt K, Schwerd T, Werkstetter KJ, et al. Repeated exclusive enteral nutrition in the treatment of paediatric Crohn's disease: Predictors of efficacy and outcome. Aliment Pharmacol Ther 2014;39:1398-407.

31. Levine A, Turner D, Pfeffer Gik T, et al. Comparison of outcomes parameters for induction of remission in new onset pediatric Crohn's disease: Evaluation of the porto IBD group "growth relapse and outcomes with therapy" (GROWTH CD) study. Inflamm Bowel Dis 2014;20:278-85.

32. Yamamoto T, Shiraki M. Long-term efficacy of enteral nutrition for patients with Crohn's disease. Dig Dis Sci 2012;57:3310-1; author reply 1 .

33. Konno M, Takahashi M, Toita N, Fujiwara SI, Nojima M. Long-term therapeutic effect of maintenance enteral nutrition for Crohn's disease. Pediatr Int 2015;57:276-80.

34. Duncan H, Buchanan E, Cardigan T, et al. A retrospective study showing maintenance treatment options for paediatric CD in the first year following diagnosis after induction of remission with EEN: Supplemental enteral nutrition is better than nothing! BMC Gastroenterol 2014;14:50.

35. Navas-Lopez VM, Blasco-Alonso J, Maseri SL, et al. Exclusive enteral nutrition continues to be first line therapy for pediatric Crohn's disease in the era of biologics. An Pediatr (Barc) 2014: S1695-4033(14)00137-4.

36. Gupta K, Noble A, Kachelries KE, et al. A novel enteral nutrition protocol for the treatment of pediatric Crohn's disease. Inflamm Bowel Dis 2013;19:1374-8.

37. Alves A, Panis Y, Bouhnik Y, Pocard M, Vicaut E, Valleur P. Risk factors for intra-abdominal septic complications after a first ileocecal resection for Crohn's disease: A multivariate analysis in 161 consecutive patients. Dis Colon Rectum 2007:50:331-6.

38. Guo Z, Wu R, Zhu W, et al. Effect of exclusive enteral nutrition on health-related quality of life for adults with active Crohn's disease. Nutr Clinical Pract 2013;28:499-505.

39. Afzal NA, Van Der Zaag-Loonen HJ, Arnaud-Battandier F, et al. Improvement in quality of life of children with acute Crohn's disease does not parallel mucosal healing after treatment with exclusive enteral nutrition. Aliment Pharmacol Ther 2004;20:167-72.

40. Gerasimidis K, Nikolaou CK, Edwards CA, McGrogan P. Serial fecal calprotectin changes in children with Crohn's disease on treatment with exclusive enteral nutrition: Associations with disease activity, treatment response, and prediction of a clinical relapse. J Clin Gastroenterol 2011;45:234-9.

41. Buchanan E, Gaunt WW, Cardigan T, Garrick V, McGrogan P, Russell RK. The use of exclusive enteral nutrition for induction of remission in children with Crohn's disease demonstrates that disease phenotype does not influence clinical remission. Aliment Pharmacol Ther 2009;30:501-7. 
42. Afzal NA, Davies S, Paintin M, et al. Colonic Crohn's disease in children does not respond well to treatment with enteral nutrition if the ileum is not involved. Dig Dis Sci 2005;50:1471-5.

43. Grogan JL, Casson DH, Terry A, Burdge GC, El-Matary W, Dalzell AM. Enteral feeding therapy for newly diagnosed pediatric Crohn's disease: A double-blind randomized controlled trial with two years follow-up. Inflamm Bowel Dis 2012;18:246-53.

44. Knight C, El-Matary W, Spray C, Sandhu BK. Long-term outcome of nutritional therapy in paediatric Crohn's disease. Clin Nutr (Edinburgh, Scotland) 2005;24:775-9.

45. Levine A, Milo T, Buller H, Markowitz J. Consensus and controversy in the management of pediatric Crohn disease: An international survey. J Pediatr Gastroenterol Nutr 2003;36:464-9.

46. Stewart M, Day AS, Otley A. Physician attitudes and practices of enteral nutrition as primary treatment of paediatric Crohn disease in North America. J Pediatr Gastroenterol Nutr 2011;52:38-42.

47. Day AS, Stephenson T, Stewart M, Otley AR. Exclusive enteral nutrition for children with Crohn's disease: Use in Australia and attitudes of Australian paediatric gastroenterologists. J Paediatr Child Health 2009;45:337-41.

48. Gerasimidis K, Bertz M, Hanske L, et al. Decline in presumptively protective gut bacterial species and metabolites are paradoxically associated with disease improvement in pediatric Crohn's disease during enteral nutrition. Inflamm Bowel Dis 2014;20:861-71.

49. Wu GD, Chen J, Hoffmann C, et al. Linking long-term dietary patterns with gut microbial enterotypes. Science 2011;334:105-8.

50. De Filippo C, Cavalieri D, Di Paola M, et al. Impact of diet in shaping gut microbiota revealed by a comparative study in children from Europe and rural Africa. Proc Natl Acad Sci U S A 2010;107:14691-6.

51. Ridaura VK, Faith JJ, Rey FE, et al. Gut microbiota from twins discordant for obesity modulate metabolism in mice. Science 2013;341:1241214.
52. Faith JJ, Guruge JL, Charbonneau M, et al. The long-term stability of the human gut microbiota. Science 2013;341:1237439.

53. Cameron FL, Gerasimidis K, Papangelou A, et al. Clinical progress in the two years following a course of exclusive enteral nutrition in 109 paediatric patients with Crohn's disease. Aliment Pharmacol Ther 2013;37:622-9.

54. de Bie C, Kindermann A, Escher J. Use of exclusive enteral nutrition in paediatric Crohn's disease in The Netherlands. J Crohns Colitis 2013;7:263-70.

55. Griffiths AM, Ohlsson A, Sherman PM, Sutherland LR. Meta-analysis of enteral nutrition as a primary treatment of active Crohn's disease. Gastroenterology 1995;108:1056-67.

56. Tung J, Loftus EV Jr, Freese DK, et al. A population-based study of the frequency of corticosteroid resistance and dependence in pediatric patients with Crohn's disease and ulcerative colitis. Inflamm Bowel Dis 2006;12:1093-100.

57. Krupoves A, Mack DR, Seidman EG, Deslandres C, Bucionis V, Amre DK. Immediate and long-term outcomes of corticosteroid therapy in pediatric Crohn's disease patients. Inflamm Bowel Dis 2011;17:954-62.

58. Lichtenstein GR, Feagan BG, Cohen RD, et al. Serious infection and mortality in patients with Crohn's disease: More than 5 years of follow-up in the TREAT registry. Am J Gastroenterol 2012;107:1409-22.

59. Terry A, Grogan JL, Casson DH, Dalzell AM, El-Matary W. Tube feeding therapy in paediatric Crohn's disease. Aliment Pharmacol Ther 2011;34:260-1; author reply 1.

60. Zallot C, Quilliot D, Chevaux JB, et al. Dietary beliefs and behavior among inflammatory bowel disease patients. Inflamm Bowel Dis 2013;19:66-72.

61. Richman E, Rhodes JM. Review article: Evidence-based dietary advice for patients with inflammatory bowel disease. Aliment Pharmacol Ther 2013;38:1156-71. 


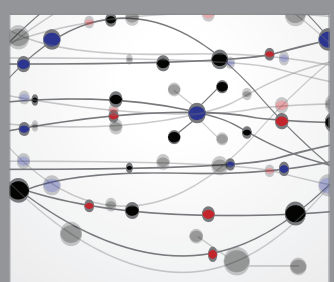

The Scientific World Journal
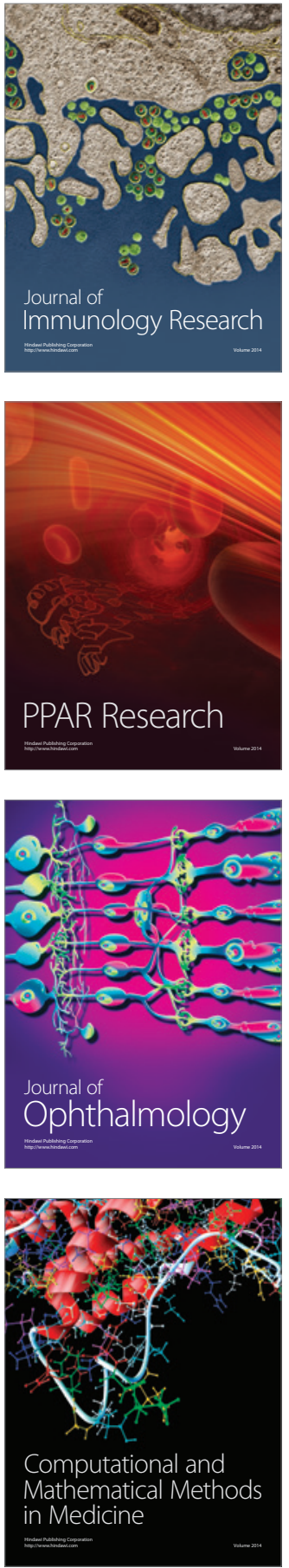

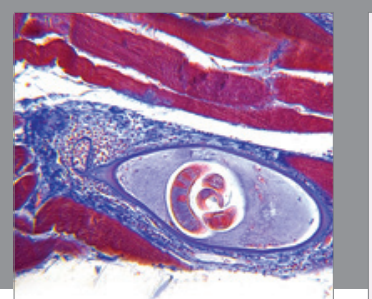

Gastroenterology Research and Practice

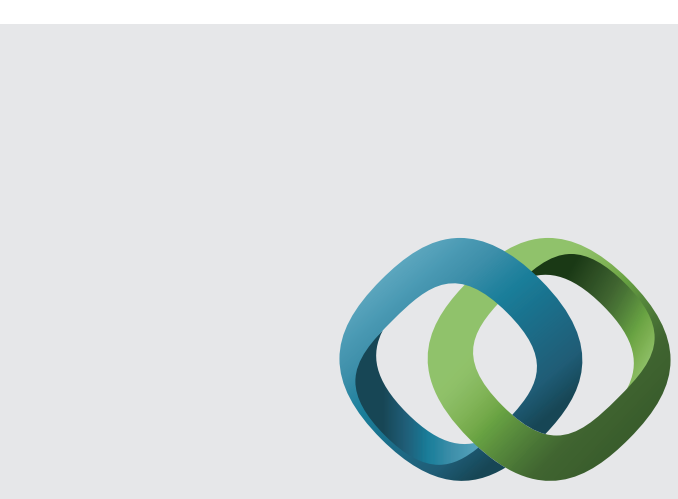

\section{Hindawi}

Submit your manuscripts at

http://www.hindawi.com
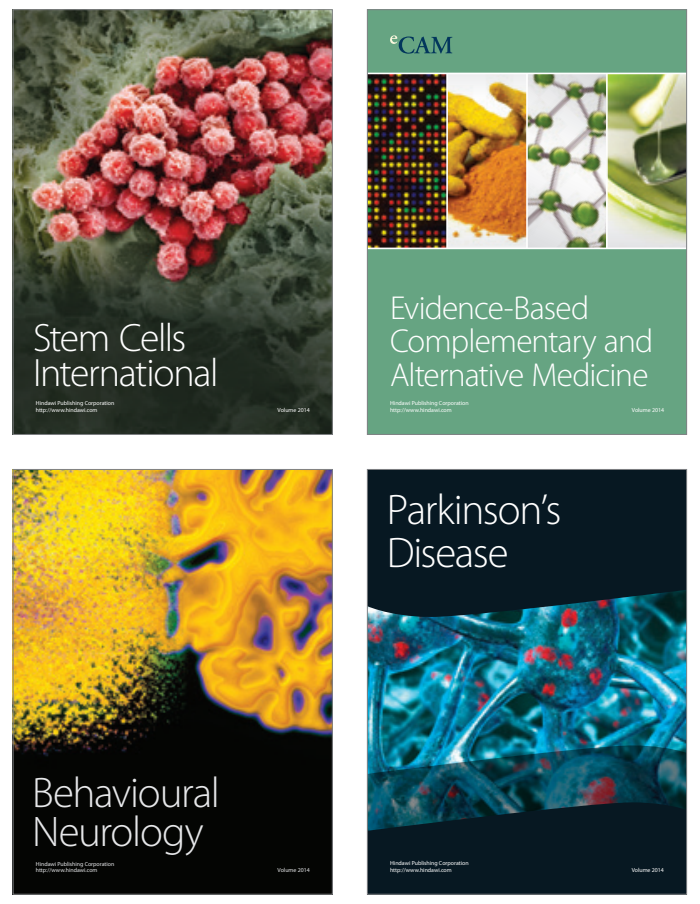
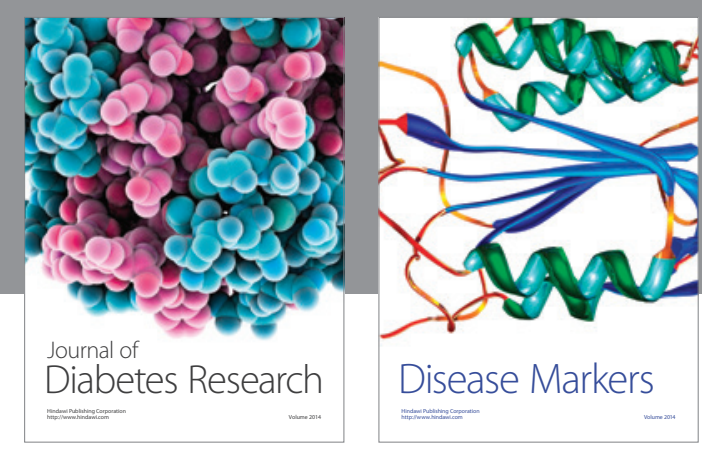

Disease Markers
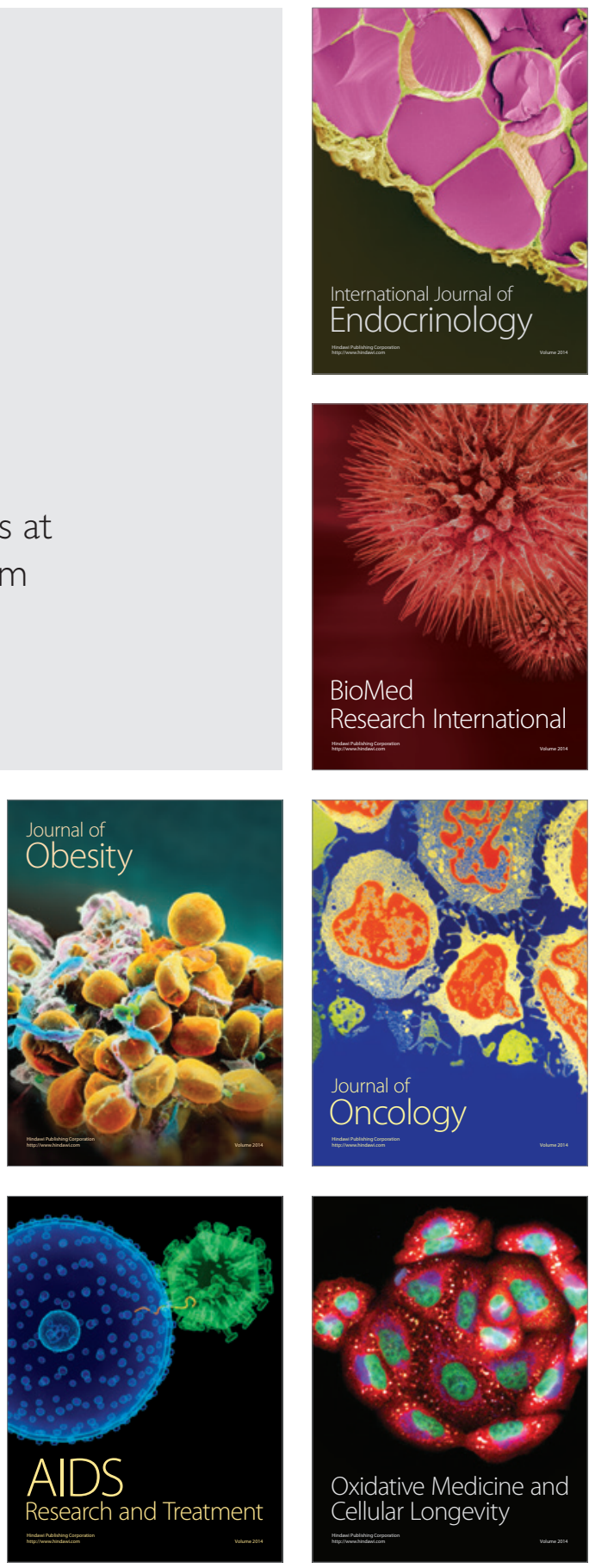